\title{
Unspecified Atypical Cells Present
}

National Cancer Institute

\section{Source}

National Cancer Institute. Unspecified Atypical Cells Present. NCI Thesaurus. Code C148407.

A finding indicating that abnormal cells with indeterminate morphological features are present in a sample. 